\title{
Can Social Interaction Skills Be Taught by a Social Agent? The Role of a Robotic Mediator in Autism Therapy
}

\author{
Iain Werry, Kerstin Dautenhahn, Bernard Ogden and William Harwin
}

\begin{abstract}
Increasingly socially intelligent agents (software or robotic) are used in education, rehabilitation and therapy. This paper discusses the role of inter-active, mobile robots as social mediators in the particular domain of autism therapy. This research is part of the project AURORA that studies how mobile robots can be used to teach children with autism basic interaction skills that are important in social interactions among humans. Results from a particular series of trials involving pairs of two children and a mobile robot are described. The results show that the scenario with pairs of children and a robot creates a very interesting social context which gives rise to a variety of different social and non-social interaction patterns, demonstrating the specific problems but also abilities of children with autism in social interactions. Future work will include a closer analysis of interactional structure in human-human and robot-human interaction. We outline a particular framework that we are investigating.
\end{abstract}

\section{Introduction}

Increasingly new technologies are used in educational and therapeutic contexts, among them socially intelligent agents, i.e. agents that show aspects of human-style intelligence [Dautenhahn 98, 99b]. New classrooms are designed, involving computer technology in order to facilitate learning, creativity and collaboration among children [Bobick et al. 99]. The NIMIS project gives an example where virtual worlds are designed as places of imagination, virtual and interactive theatres where children can create and explore their own stories [Machado \& Paiva 00]. Carmen's Bright Ideas is an interactive animation simulating a counseling session for mothers whose children undergo cancer treatment [Marsella et al. 00]. It is hoped, that by getting engaged in the scenario, users empathize with its characters and can reflect on their own situation by assisting the virtual characters in their decisions. For many years LOGO/LEGO systems with physical or simulated robots have been used in education, supporting an exploratory, constructionist approach towards learning [Papert 80]. In recent years a new generation of interactive social robots has been designed as re-search platforms [Breazeal \& Scassellati 99], toys (e.g. Sony's Aibo, the Robota dolls [Billard 00]) or educational tools [Druin \& Hendler 00; Cooper et al. 99]. Such robots are specifically designed for interactions with humans, and often interactivity is the primary purpose. Social robots are therefore clearly different from service robots that may or may not interact with people, but which are primarily designed for a particular purpose such as a tour guide [Schulte et al. 99]. 
For many years computer and (more recently) virtual environment technology is used in autism therapy, see e.g. [Colby \& Smith 71; Colby 73; Russo et al. 78; Panyan 84; Chen \& Bernard-Opitz 93; Strickland 96; Powell 96; Murray 97; Moore 98; Blocher 99; Charitos et al. 00; Parsons et al. 00]. Such work shows that many people with autism interact very 'naturally' with computer technology, and that such technology provides a safe and predictable environment that can be used in an exploratory and creative manner. A few projects also investigate robotic devices. Weir and Emanuel (1976) studied one child with autism who used a keyboard to control a re-mote-controlled robotic device. Plaisant et al. (2000) are studying how a remote con-trolled robot can teach children about emotions. Michaud et al. (2000) developed different robotic designs and did initial studies with children with autism.

This article addresses the potential of interactive, social robots as therapeutic tools or 'toys' in autism therapy, research that is done in the project AURORA. The AURORA project uses a single interactive robot and studies different scenarios in order to characterize and evaluate qualitatively and quantitatively the children's behavior when playing with the robot. The one-child-one-robot scenario is our basic approach, with the robot in the role of a therapeutic teaching device, a tool that can be used to teach children with autism basic social interaction skills. However, a second very important role of the robot that we investigate in this paper, is its role of a social mediator, a tool that mediates (encourages and facilitates) social behavior among children, and among children and adults. In designing such a social mediator it is important to study carefully how children with autism interact with the robot, how their particular difficulties and abilities influence the interactions, and how the robot can be used so as to encourage particular 'desirable' types of interactions, i.e. interactions that children with autism might generalize, and that then could help in daily interactions with humans outside the classroom context.

\section{The AURORA Project}

The AURORA project was initiated in 1998, with the goal of developing a robotic agent which would aid in the therapy of children with autism.

According to the National Autistic Society, children with autism show impairments in three key areas: social interaction, social communication and imaginative play. Additionally, these children appear to find comfort in repetitive and monotonous activities, and avoid the complex interactions involved with people, whether they are teachers or relatives. This leads to an inhibited ability in social situations, which provokes fear and further avoidance.

The aim of the AURORA project is to provide both a mediator and teaching aid for the children, giving them an opportunity to practice and explore their behavior in social situations, as well as to provide a focus of interest and attention for the children in order to stimulate interpersonal relations and interactions. Also, a robotic agent has the properties of repeatability and stability, while presenting communication along a limited number of channels, and robots have become familiar to children through television and the media. These factors allow the children to relate to the robot on a simple level, without the fear and complexity of human interaction, and allow the children to learn simple skills such as role-playing and turn-taking games. The robot should be used by the teachers and be flexible enough to reach a number of children's 
levels, not replacing the personal interaction common in classes and traditional therapy methods, but providing an additional tool. More details about the project's back-ground, objectives, the robot used in the trials, and autism therapy are given in [Dautenhahn 99; Werry \& Dautenhahn 99, 00, 01; Werry et al. 01].

\section{The Two-Children-One-Robot Case Study}

A number of trials have been performed to date. The trials involve children with autism between 8 and 12 years of age, mostly male (all children reported on in this paper are male). Trials at an early stage in the project were intended to gauge the level of interaction to be expected from the children and to provide a baseline for further development work. The first positive result was that the children were not afraid to interact and approach the robot. This was an important result as, if the children had been cautious of the robot, then the interaction would not have been comfortable and natural for them.

Later trials were performed to evaluate the type and nature of the interactions involved in order to direct further development. Trials were structured to allow the children to interact with the robot as they would in a natural environment, with a minimum of guidance. The robot that is currently being used in the project is small mobile robot with 8 infrared sensors positioned around its body and 1 positional heat sensor mounted at the front. Its dimensions are $38 \mathrm{~cm}$ by $30 \mathrm{~cm}$ by $21 \mathrm{~cm}$. It is very robust and relatively lightweight $(6.5 \mathrm{~kg})$. A speech box has been added to the robot so that it is able to producing speech, i.e. certain phrases such as 'I can't see you', triggered by the robot's own state and the way children interact with it.

One series of trials studied how children with autism interact with the mobile robot as opposed to a non-robotic toy [Werry et al. 01]. Here, a quantitative evaluation technique based on micro-behaviors was developed. By applying the quantitative evaluation technique, interaction patterns of individual children could be characterized, data necessary for further studies. This article focuses on a particular series of trials with pairs of children, investigating the role of a mobile robot as a social media-tor. For this particular series of trials it seemed important to go beyond a micro-level of description and study patterns of interaction that focus on the social level. Results are therefore presented qualitatively in the format of descriptive narratives.

\subsection{Setup}

The trial sessions took place in a room at the children's school (Radlett Lodge School, Hertfordshire, United Kingdom). This has the advantages that the children are not required to move out of the building, the disruption to their normal classes is minimal, and the environment is known to them. These factors reduce anxiety and allow the children to behave and interact without additional distractions and also allow the staff of the school to be present as advisors.

The room used was approximately three meters by four meters in size, and had a single door and a single window, overlooking the school car park. The only features present in the room were chairs for the experimenters, and the robot. Also present was a member of staff from the school, who arrived with the 
children and was familiar with them. They were on hand to advise on the mood of the children and when to terminate the trial, as well as to restrain and provide occasional interaction and prompts with the children. Two experimenters were also present in the room, al-though they restricted their actions to documenting the trials with a video camera and to assist the robot when it inevitably became overturned or switched off.

Six children participated in the trials, in three pairs. These children had been selected prior to the trial session by the teachers of the school. The children consisted of four who had had a previous experience with the robot, and two who had not seen or interacted with the robot before. The children were chosen on the basis that they would provide an interesting response with the robot, either because they enjoyed technology or because they were more outgoing. Additionally, the pairing of the children was also performed by the teachers, based partially on which children would provide 'interesting' pairings and which were available at the same times and could be brought out of their normal class without disruption. It should be noted that this selection method is preferential to children who are of a higher functioning level, as these children are able to tolerate a disrupted schedule and are automatically selected by the teachers for their interaction abilities.

The robot is programmed using a behavior-based architecture (e.g. [Arkin 98]). It performs a number of actions, primary among these are avoidance of obstacles, including people, following of a heat source and the generation of simple speech and phrases. These behaviors allow the robot to follow and to be chased by the children, while at the same time producing brief utterances for those children who are able to respond to speech. The result of this is a robot which provokes responses from the children and is pro-active in its interaction by moving towards the children and prompting by the use of speech.

Within these confines, the children are able to perform any action or behavior which would not damage either the robot, themselves or the environment. Other members of staff at the school were seated outside the room and so the children were even able to leave the room if they wished. No pressure was placed on the children to perform a specific type of interaction or behavior, or even to interact with the robot at all. This is due to the fact that any type of interaction was welcomed as informative on the state of the robot and the development and ability level of the children. The trials lasted until either the teacher or one of the experimenters requested an end, due to the state of the robot or the emotional state of the children. On average, the trials lasted nine minutes.

\subsection{Results}

\subsubsection{First Pair - Child A, Child B}

While child A only started at the school only 2 months before the trial, this pairing was the strongest socially of the trial pairs. The trial started with child $B$, who had encountered the robot previously, entering the room and commenting on its ability and speed compared to an earlier trial, without directly interacting with the robot. Child $A$ then entered the room and watched the robot until child $B$ pointed and drew attention to it. Both children then watched the robot as it moved around them, and child $B$ questioned the experimenters about the robot's designers. Child $A$ then questioned the experimenters, who he had not previously met, and child B intercepted the robot as it headed towards the 
door, and picked up the robot to turn it around. The robot then uttered a phrase, which child $A$ heard and became excited with. He then questioned the experimenters about the robot's speech, and directly interacted with the robot to bring it into the center of the room. Both children then watched the robot. Child $A$ then knelt down to look at the robot more closely while child $B$ asked questions about the sensors on the robot and picked it up briefly. Child $A$ then tentatively touched the robot. Both children became puzzled when the robot stopped moving and moved in front of it at the experimenters' suggestion.

Child A seemed continually fascinated by the robot's speech and crawled around to look at it. He then backed away from the robot in an effort to avoid it and continued to move away when it followed him. When the robot lost him, he moved back into range and then away again in order to allow the robot to continue to follow him. At this point, child A noted that one of the wheels of the robot was loose and falling off and an experimenter intervened to fix the robot. The children seemed to lose interest in the robot as it was being repaired, and focused their attention on one of the, now unattended, video cameras.

When the robot was again ready, both children transferred their attention back to it, and child $A$ asked what the name of the robot was. Child $B$ then tried to get the attention of the robot by tapping on the top of it. He then asked about other programs for the robot and child $A$ asked about the buttons at the rear of the robot, child $B$ answered that they were for re-programming. Child $B$ continued to wonder about other programs for the robot and showed one of the experimenters his 'Robot Wars' hat.

Child A appeared to grow tired with the robot and jumped over it before leaving the room to talk to the teaching staff who were observing outside the room. He came back into the room and the children discussed what else the robot should do. Both children then attempted to make the robot follow them simultaneously.

The children then talked about what they would like the robot to be able to do and one of the experimenters showed the children how they were able to chase the robot by moving close to it, which child $A$ then tried to do. Both children talked about robots that they had seen and things that they would like the robot to do and child $A$ then showed child $B$ how to chase the robot. At this point, the wheel again fell off the robot and the trial session was ended.

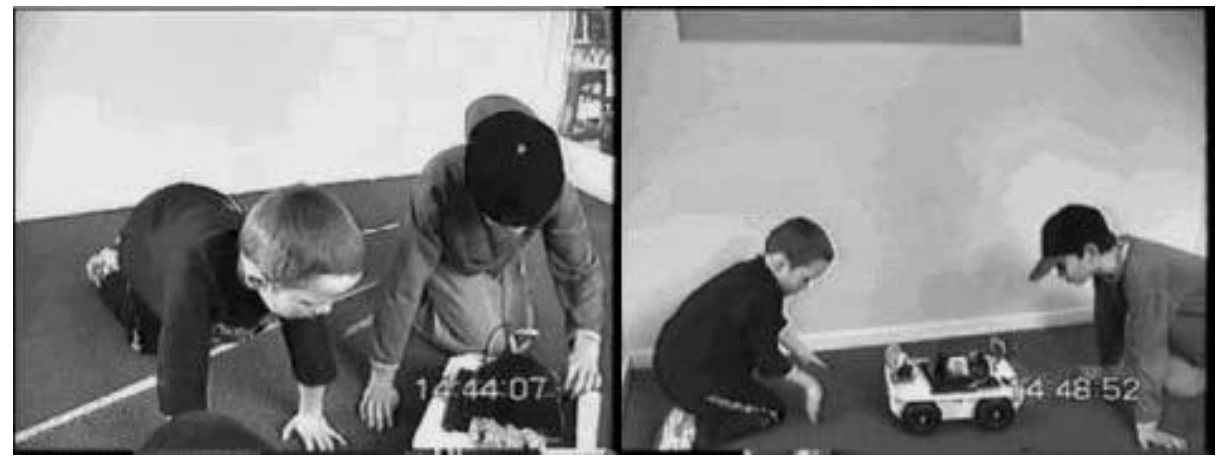

Fig. 1. Child $A$ and child $B$ playing with the robot

The trial showed a number of positive results and the children were reasonably social and interactive, both with the robot and with each other. Both 
children were vocal and talked both about and to the robot throughout the session, in particular about what the robot 'should' do, and both children became excited with the robot. The children were uninhibited with the robot and were able to interact naturally, by touching and operating it. In particular, the robot provided a platform for interaction in the case of the children chasing it. This was demonstrated to child A who then instructed child $B$, suggesting learning by imitation and social interaction. The fact that these children were naturally quite sociable with each other was demonstrated in the session and they were obviously comfortable together.

The robot was a strong focus for child-child interaction and child-robot interaction and it worked well in promoting interaction generally. However, it should be noted that the children were of a higher functioning level than the other pairs in the trial and this may influence the number and types of interactions observed.

\subsubsection{Second Pair - Child C, Child D}

The second pair of children also consisted of one child who had encountered the robot before (child C), and one who had not (child D). Child C had recently become interested in the car park and the cars outside of the building, while we were told that child $D$ had little interest in people generally unless they functioned as an audience for him. Additionally, child D arrived at the school only one month previously, and both the children were in the same class and so were familiar with each other, al-though they were not as strong socially as the previous pair.

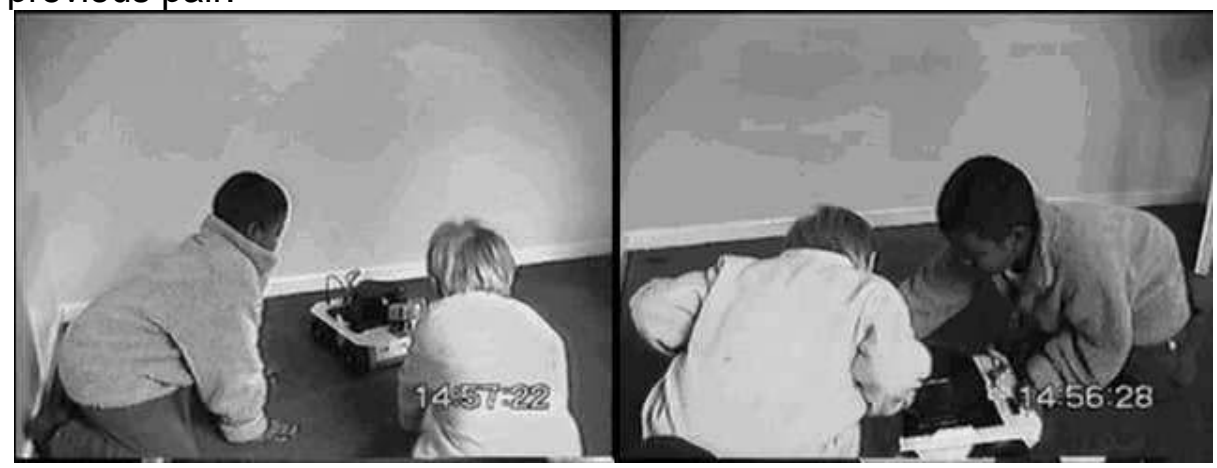

Fig. 2. Child B and child $C$ playing with the robot

Child C was instantly interested in the robot and immediately started to push and touch it - interactions which had been prevalent in the previous trials. When child $D$ entered the room, he circled the robot and stood watching as child $\mathrm{C}$ pushed it. When it began to speak, child $\mathrm{D}$ bent down to tell the robot to 'rip up the carpet'. Both children interacted with the robot simultaneously, but without interacting with each other. As the robot became stuck against the wall both children pushed it away, and watched as it moved around a little. Child D was aware that the robot was able to locate him and asked how this was possible. He then became agitated about the robot's speech as child $\mathrm{C}$ pushed the robot again.

The teacher present calmed child $D$ a little and drew attention again to the robot. Child $D$ again told the robot to 'rip up the carpet' and both children touched and interacted with the robot but without acknowledging each other, however while child $\mathrm{C}$ pushed the robot, child $\mathrm{D}$ was forced to move in order to stay in front of the robot. 
The teacher again drew the attention of child $D$ to the robot's speech, while child $C$ sat to the side. Child $D$ then circled the robot and child $C$ pushed it a little, which continued as child D talked to the teacher about the robot and its abilities.

Both children then appeared to grow bored and their attention shifted to other parts of the room. Child D then picked up the robot and the teacher took it off him, and child C walked around the room. With neither child in front of it, the robot stopped moving and child D asked why this had happened. The robot then moved towards the teacher and child $D$ asked it if he could go home. Child $\mathrm{C}$ moved to the window and spent the majority of the remainder of the session watching the car park, and child D got closer to the robot and interacted with it by touching it, forcing it to become stuck by obstructing it.

When the robot was again able to move, child $D$ chased and started to push it around, as child $\mathrm{C}$ had done at the beginning of the trial. He then became interested in the buttons on the rear of the robot and turned it off. The teacher was able to restart the robot, and child $D$ then shouted at it in an attempt to get it to move. He then be-came hyperactive and began shouting. He was then instructed by the teacher to 'be nice' to the robot and ignored or watched it without any direct interaction.

This session demonstrated the common phenomenon of non-social play, both children attempted to interact with the robot without acknowledging the presence of the other. They were able to do this only to a certain degree; however, with one robot and two children, situations occurred where this was not completely possible, as one child moved the robot the second was forced to move in turn to be able to interact with it. This is an area which demands further research as it may provide a means of encouraging social interaction in children with autism.

This pair of children interacted with the robot at a lower level (compared to the previous pair), for example treating it as a toy and pushing it around the floor. It is important that the robot is robust enough to withstand this type of operation. Child $\mathrm{C}$ became interested in the car park towards the end of the session and this restricted the interactions with the robot. Previous trials have taken place in a room without an external window and so this type of distraction has been limited.

\subsubsection{Third Pair - Child E, Child F}

This pairing was the least social, although both children are in the same class as the first pair and both had encountered the robot in previous sessions. The session began with child $E$ interested in the robot and manipulating the robot's front sensor to point in different directions, while child $F$ seemed uninterested in the robot, and interacted with the teachers outside the room. The robot then backed away from child E, who extended his arms as it moved and then withdrew from the robot so that it moved towards him again, as he did this he told the robot to 'leave me alone'. He then repeated this interaction but moved his whole body position towards and away from the robot. Child $F$ then re-entered the room and put a foot on the robot, without acknowledging the presence of child $E$. Child $E$ continued to dominate the interaction with the robot while child $\mathrm{F}$ walked around the robot and ignored the play in the center, before again leaving the room. All this time, child $E$ operated the robot through his relative position with it and gave it vocal commands and directions of movement. As child $\mathrm{F}$ again entered the room, child $\mathrm{E}$ became interested in the door and this allowed child $F$ to become focused on the robot a little more, 
crouching down and looking at it more closely. Child $E$ then resumed his interaction, giving the robot vocal commands while moving towards it, and child $F$ diverted his attention away from the robot and again moved around the room.

When the robot spoke, child $\mathrm{F}$ seemed pleased and approached the robot once again, even though child $E$ was still interacting with it, and then moved away again. He approached the robot again when it said the same phrase and examined it and touched it. Child $E$ then obstructed the hands of child $F$ and took control of the robot and pushed it. Child $F$ again touched the robot and child $E$ again pushed his hand away, as the robot moved between them. Child $E$ again obstructed child $F$ from touching the robot and told child $F$ to "leave him alone', even mentioning the name of child F to instruct him not to touch the robot.

Child $F$ then backed away from the robot and observed the interaction between it and child $E$, before again touching the robot and again being told to 'leave that alone' and 'leave him alone' by child E who again mentioned the name of child F. Child $E$ also used his body to obstruct child $F$ and pushed him away bodily. Child E also pointed out the robot's sensor as its 'eyes'.

Child $E$ then backed away from the robot, and walked around it, and asked it for its name. Child $F$ again lost interest in the robot and started to ask the teacher about the window and to walk around the room. Child $E$ then started to overturn the robot, and one of the experimenters was forced to intervene to avoid the robot becoming damaged, turning it right way up again.

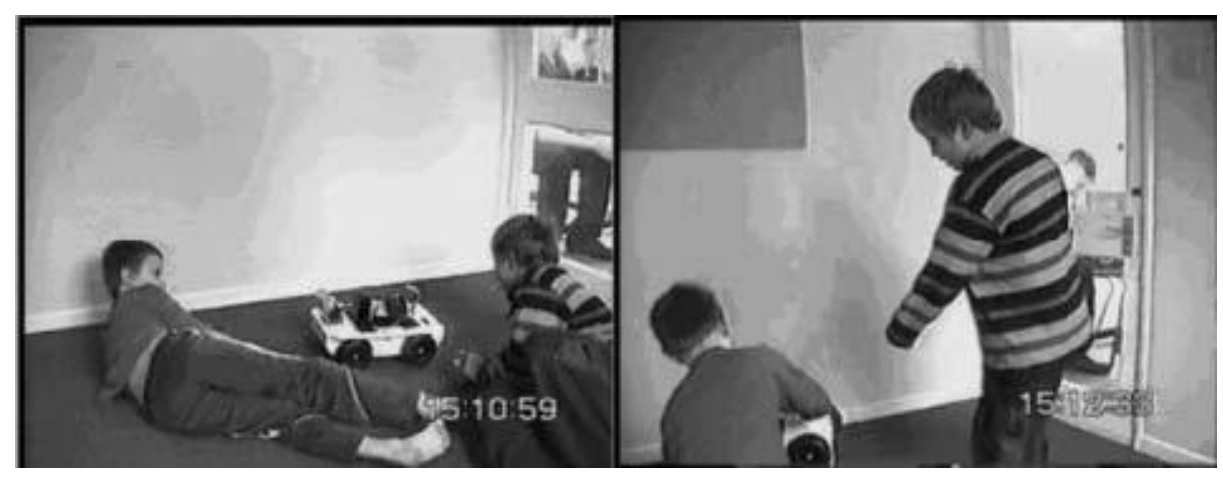

Fig. 3. Child $E$ and child $F$ playing with the robot

Child $\mathrm{F}$ continued to circle the robot as child $\mathrm{E}$ watched and waited for the experimenter to replace the heat sensor which had become dislodged. When this was done, child $E$ interacted with the robot and again obstructed child $F$, again began to overturn the robot and again the experimenter was forced to intervene. This pattern was repeated a third time and a fourth before the session was ended.

This session shows a repeating pattern of interaction: child $E$ is dominant in the interaction and does not allow child $F$ to interact. However, he waits for the experimenter to finish with the robot when the robot becomes overturned. He is also relatively vocal and in his obstruction of child $\mathrm{F}$ becomes social. He also displays a variety of interactions with the robot and understands how to operate it and that it will follow and avoid him. Child $F$ became interested in the robot initially after it provided verbal stimulus, and takes opportunities to interact with the robot when child $E$ is otherwise occupied or distracted. 


\subsection{Discussion of Results}

These trial sessions resulted in a number of important points. Something which is perhaps not initially obvious is that the social relationships between the children were preserved. While the children did not show a marked increase in their sociability, the fact that they behaved in the same way as they do in other situations and that their social interactions, and lack of them, was preserved shows that the robot scenario did not present an entirely different environment for them. This result is particularly important given the autistic child's inhibited ability to generalize, with any ability learned in a certain environment not being carried to a second, different environment. This means that there is an increased possibility of any developments made with the robot to be used in other situations.

Secondly, the ability of the robot to provide a focus of attention and shared attention was demonstrated in the first pair, as an experimenter showed child $A$ how to interact with the robot by demonstrating that it would back away from objects. Later in the session, child $A$ then explicitly demonstrated this in order to instruct child $B$, showing social interaction, social learning (possibly imitation) and demonstration of a new skill. All of these areas are known to be difficult for children with autism [Jordan 99, Nadel et al. 99].

The role of the robot as a mediator also became apparent in a number of situations where the children interacted with the teachers about the robot. A number of the children asked the teacher present about the robot and it became the focus of attention for child-teacher interaction, child-experimenter interaction and child-child interaction. For example, both the children in the first pair discussed the robot with the experimenters, talking about what it is and is not able to do, as well as what they thought that it should do.

Additionally, the fact that children with autism are generally seen to play non-socially was observed in the trial sessions. Both children in each pair only had a single robot and no other items to play with. This lead to the situation where both children attempted to use the robot individually and in isolation of each other, inevitably leading to conflicts. Future developments of the robot could take advantage of this situation, providing a method of interaction which would allow two children to operate the robot simultaneously. This would mean that the children would not directly interact with each other, but would do so through the robot as a mediator. Such scenarios could support the transition from non-social play (a child playing alone with the robot), to non-interactive play (both children playing with the robot simultaneously but without interaction between them), to social and interactive play (the children playing with each other, with or without the robot as a toy).

The preconceptions about robots carried by the children also influenced their interaction, with the first pair discussing the television program 'Robot Wars' with the experimenter and with child D instructing the robot to become destructive. This can be an important factor in exactly what the children expect from the robot and the ways in which they expect to be able to interact with it. However, the fact that the robot was not destructive did not seem to inhibit the interaction greatly, except in a few cases where the children asked the robot to perform some specific actions.

In general, the behaviors implemented on the robot performed well. A few of the children were aware that the robot is able to follow them and that they are also able to chase it. Also, a few children were able to learn this, both through instruction and through learning by observation. An important fact is that the 
interactions with children who did not make use of the follow and chase behaviors were not obstructed by these behaviors. For example, child $\mathrm{C}$ was able to push the robot around without interference from the robot's behaviors. The robot's ability to produce speech had an impact on the interactions. While the children did not seem to use the speech for their direct interactions, a number of children became drawn to the robot after they learned that it produced verbal comments. This initiated further interactions and prompted a closer inspection by the children. In this respect, the actual phrases produced by the robot seem to be less important than the fact that the robot is able to speak. A few of the children attempted to operate the robot through the use of vocal commands, which were ineffectual and if implemented the robot would unlikely be able to obey them as they were relatively complex. In this way, the use of verbal commands for the robot seems to have a limited potential. It should also be remembered that children with autism can have a large range of abilities and reactions. To simply develop the ability of the robot to obey speech commands would neglect those children who are non-verbal. Similarly, to expand the speech produced by the robot is to risk children of a lower ability becoming afraid and confused with the robot, and the speech becoming too distracting.

\section{A Closer Look: Interactional Structure and Implications for Robot-Human Interaction}

The qualitative and rather macro-level descriptions given in section 3 reveal that during interactions of the children with the robot very interesting types and structures of interaction can be observed (such as instruction, cooperation, possibly imitation etc.). In the long-term we hope that a) knowledge about such structures will help us in the development of a vision system that can automatically identify and track certain interaction patterns with therapeutic relevance which will aid the evaluation of trials tremendously, and b) that knowledge about interactional structures will allow us to make the robot more 'socially responsive', going beyond reactive, behavior-based interaction. Such issues are addressed in the interactive vision project [Ogden \& Dautenhahn 01a, 01b] which is a sub-part of the AURORA project and explores the interactional structure of human-human and human-robot interaction in more detail, strongly inspired by literature from sociology, psychology and anthropology. This section will outline the main issues and concepts that we identified as important ingredients of a framework of interactional structure that we will investigate in the context of interactions of children with autism with robots.

Generally, humans as one kind of interactive system are very advanced and it is certainly unrealistic at the present time to develop robotic systems based on many aspects of human interactional structure: for example, human interactional 'rules' must be applied according to the current context [Button 90], where context has a number of specific meanings including the personality and history of the interactants, the relationship between interactants, the physical nature of the place in which the interaction is occurring and the type of institution and culture in which the interaction is taking place. In order to apply knowledge on interactional structures to scenarios studied in the AURORA project the complexity of human interactional behavior needs to be reduced so that we can realistically deal with it. We propose achieving this in two ways: by 
viewing interaction as locally structured and by dealing with interaction only at a metacommunicative level. We believe that this allows us to develop a system that is simple enough that it can realistically be implemented at the present time but that is sufficiently advanced to both provide the basis for a system that will extend the interactive capabilities of robots and provide a useful framework for understanding robot-human interaction. Also, on a conceptual level, a focus on locally structured interaction and a subsemantic level better fits a bottom-up view on human social behavior, and human intelligence in general [Dautenhahn 97, 99]. Such a view means that we are particularly interested in emergent properties in human-human and human-robot interaction, with a focus on interaction dynamics and changes in interaction structures over time.

\subsection{Globally Structured Interactions}

Viewing interaction as locally structured contrasts with the globally-structured view of interaction, which is perhaps best exemplified by the concept of scripts [Schank \& Abelson 77]. While scripts were not specifically designed to explain human interaction, they are an ideal way to view globally structured human interaction. In this view a given type of interaction has an associated script specifying the actions that should occur as the interaction progresses. Kendon's example of the structure of greeting interactions [Kendon 90] may be viewed in this way (although Kendon's own perspective on the way that interaction is structured seems closer to a locally structured view [Kendon 80]): in this example a greeting can be divided into three primary phases: distance salutation, approach and close salutation. Each of these phases has particular behaviors associated with it and once a greeting is begun then each phase will be carried out in turn, in a global view of interactional structure. In the present case, however, this view of interaction seems difficult to apply: as the above examples indicate, the interactions between child and robot are inherently freeform and we are left with the task of clearly defining the detailed structure of a very broad, loosely defined interaction ('play') or of preparing a number of simpler structures reflecting events that tend to occur, such as the chase game played by child A. While this is an option, it would be preferable to take a more flexible approach that does not require us to detail a set of actions that are supposed to occur from beginning to end. General limitations in using this 'global' approach are considered in [Ogden \& Dautenhahn 00].

\subsection{Locally Structured Interactions}

In a local view of interactional structure, by contrast, actions are influenced by immediately preceding actions. Overall structure is not considered and we have little concern with 'expected future actions' beyond the immediate next action. Also, while not denying the importance of the history of an interaction to the current action we can note that in many cases the immediately preceding action is the one of primary importance (e.g. if a question is asked, most of the time we will expect it to be answered), allowing us to focus in most cases on immediately preceding and following actions. A view of interaction as locally structured is prevalent in the field of conversation analysis [Psathas 95]: in this view any given action tends to constrain the likely action taken by other interactants, as in the case of questions tending to prompt answers. This view seems promising in that actions can be considered as simple action-response 
pairs without having to consider questions of the type of interaction that is occurring: this both simplifies the structures that will need to be developed and broadens their applicability. This view also seems likely to result in more robust interactive behavior: if an interaction is expected to follow a given structure from be-ginning to end and it then deviates from that structure, it seems that this will be harder to recover from than an inappropriate response to an isolated action. In the locally structured case repair may or may not occur, but if it does not the interaction can continue without concern for what this means for some broader abstract structure. To give an example, we might have a rule that if the child approaches the robot, the robot will retreat at a similar speed to that at which it was approached (this rule is partially implicitly implemented in the existing programming of the robot, in that the robot will retreat if it is too close to an obstacle): a rule such as this allows chasing games to emerge without the need to specify an explicit 'structure of chasing' from the outset. To view the actions of the children in these terms, when child $B$ points at the robot, this serves to focus the attention of the children on the robot. This is an example of immediate, local structure: the rest of the interaction is not relevant to the effect of this pointing action.

\subsection{Meta-communicative Aspects of Interaction}

Our second means of simplifying the interaction structures is to consider metacommunicative aspects of interaction only. Generally speaking, metacommunicative refers to the 'syntax' of communication as opposed to the 'semantics'. Before proceeding it is necessary to clarify in more detail what is meant by metacommunicative. We can divide the communication in interaction into two orders of communication: the first is the explicit transfer of information between interactants e.g. the content of what is being said or the meaning of a gesture (such as "OK", or "Goodbye"). The second is what we refer to as metacommunicative and is about how the semantic component of the interaction is structured: for example, it is concerned with where turns are taken or identifying who is involved in a given interaction: unlike communicative actions involved in the transmission of semantic content, metacommunicative actions are often engaged in without any conscious awareness on the part of the sender and / or the receiver. It may be that such features of interaction as a sense of involvement in interaction and the perceived quality of an interaction are due to or at least reflected in metacommunicative behaviours [Cappella 97]. We are therefore investigating interactional structures with a simple turn-taking nature: a good example of the kind of interaction that we are interested in is described in [Dautenhahn 99b] which studies temporal coordination of movements in robot-human interaction. There is no explicit semantic 'meaning' communicated in such interactions but nonetheless an interaction can be said to be taking place. In terms of generating robotic behavior we primarily focus on nonverbal communication ('body language'), which has a significant meta-communicative component. Examples of interaction with no verbally communicative component from the preceding section include the cases of the 'chasing' game and the 'following' game, both engaged in by the first pair of children in the preceding section. Here, we can assume that there is no attempt to communicate anything but an interaction is nonetheless taking place.

In addition to inspiring our approach to interactional structure, conversation analysis provides us with a means of assessing interactions between the 
children and the robot. Conversation analysis is a qualitative approach that produces detailed descriptions of interactive (not necessarily verbally communicative) behavior at a micro level. This allows detailed analysis of an interaction in the context in which it occurs and also allows structures present in the interaction to be discovered without any theoretical presuppositions being made: in this way what is actually present in the interaction can be discovered without concern that we are being guided to see structure that is not really present by theoretical assumptions. In the case of the above interactions this allows us to see structures and details that might be missed at a higher level of description. In addition to conversation analysis other, more quantitative, approaches are available: for instance, the Theme package [Magnusson 96] finds statistically significant temporal structure in behavior. We see these approaches as complementary and hope to explore the use of each to determine its suitability for the present project.

Detailed analyses of the structure of interactions such as those presented above will allow us to determine the kinds and complexities of interactions that are occur-ring. This, in turn, will allow us to develop the 'social interaction skills' of the robot so that children can get engaged in more advanced interactions with the robot. Even with macro-level descriptions such as those above we can get some idea of how to extend the robot: for example, if it is revealed that a child plays a game of 'chase' with the robot, as child A does in section 3.2.1 above, we can develop the robot to extend this interaction, both making it more rewarding for the child and increasing the complexity of the interaction, which will give the child experience in dealing with more advanced interactions. For example, we could extend the chase game so that the robot both runs from the child and, from time to time, turns round and pursues the child instead, or so that the speed with which the robot retreats varies according to the speed with which the child approaches. Of course it will be necessary to be careful in developing such extensions: if it seemed likely that the child would be disturbed by being chased by the robot then such an extension would obviously not be appropriate. Similarly, if we wish to encourage two children to cooperatively play with the robot we could set up the robot to preferentially respond to one child rather than the other at different points in the interaction - this may encourage different kinds of interaction than that described in Sect. 3.2.3 while encouraging the kind of interaction described in Sect. 3.2.1: equally, we could create try to create games that involve two cooperating children. While macro-analysis of the interactions allows us to propose rough advancements such as these, the micro-analyses should both inform the detailed de-sign of such advancements and will likely expose further ways in which the interactive capabilities of the robot may be usefully extended.

\section{Conclusions}

This article reported on trials that investigated the role of a mobile robot as a social mediator in autism therapy. When pairs of two children were playing with the robot interesting interaction structures were observed, such as instruction, cooperation, possibly learning by imitation, and others. Results so far are very encouraging, al-though more trials will be needed before we can draw general conclusions and long term studies need to show whether the two-children-one-robot scenario has any positive impact on the children's social or other skills. The integration of knowledge on interactional structures 
within this scenario is hoped to help us in future work on the analysis and design of robot-human interactions.

In the general context of robots that can be integrated in human society such work points towards a new potential role that robots might adopt in human society, beyond tools and appliances, a fundamentally social role. The design of such systems in different application domains such as education and therapy will require a detailed analysis of robot-human relationships, how humans perceive and respond to robots [Bumby \& Dautenhahn 99], and how a social robot, within the constraints of its particular 'purpose' for which it was designed, could meet the cognitive and social needs of human beings.

Acknowledgements. This project is supported by EPSRC GR/M62648 and con-ducted with the assistance of Radlett Lodge School of the National Autistic Society. The Labo-1 robot used in this research is donated by Applied Al Systems, Inc.

\section{References}

1 Aibo, URL: http://www.aibo.com Last referenced $23^{\text {rd }}$ March 2001.

2 Arkin, R. C. (1998) Behavior-based robotics. MIT Press, Cambridge, Mass.

3 AURORA, URL: http://www.aurora-project.com/ Last referenced $23^{\text {rd }}$ March 2001.

4 Billard, A. (2000) Play, dreams and imitation in Robota. Proc. Socially Intelligent Agents

- the Human in the Loop, AAAI Fall Symposium, Technical Report FS-00-04, AAAI Press, pp. 9-12.

5 Blocher, K. H. (1999) Affective Social Quest (ASQ) Teaching emotion recognition with interactive media and wireless expressive toys, MSc Thesis, MIT, USA.

6 Bobick, A. F., Intille, S. S., Davis, J. W., Baird, F., Pinhanez, C. S., Campbell, L. W., Ivanov, Y. A., Schütte, A., \& Wilson, A. (1999) The KidsRoom: A perceptually-based interactive and immersive story environment. Presence: Teleoperators and Virtual Environments 8(4), pp. 369-393.

$7 \quad$ Breazeal, C. \& Scassellati, B. (1999) How to build robots that make friends and influence people. Proc. IROS99, Kyonjiu, Korea.

8 Bumby, K. \& Dautenhahn, K. (1999) Investigating Children's Attitudes Towards Robots: A Case Study, Proc. CT99, The Third International Cognitive Technology Conference, August, San Francisco.

9 Button, G. (1990) Going up a Blind Alley: Conflating Conversation Analysis and Computational Modelling. In Luff, Gilbert and Frohlich (eds) Computers and Conversation, Academic Press Limited, London, UK. 10 Cappella, J.N. (1997) Behavioral and Judged Coordination in Adult Informal Social Inter-actions: Vocal and Kinesic Indicators. Journal of Personality and Social Psychology 72(1), pp. 119-131.

11 Charitos, D., Karadanos, G., Sereti, E., Triantafillou, S., Koukouvinou, S. \& Martakos D. (2000) Employing virtual reality for aiding the organisation of autistic children behaviour in everyday tasks, Proc. $3^{\text {rd }}$ Intl. Conf. Disability, Virtual Reality \& Assoc. Tech, Alghero, Italy 2000, pp. 147-152.

12 Chen, A. H. A. \& Bernard-Opitz, V. (1993) Comparison of personal and 
computer-assisted instruction for children with autism. Mental Retardation 31(6): 368-376.

13 Colby, K. M. \& Smith, D. C. (1971) Computers in the Treatment of Nonspeaking Autistic Children. Current Psychiatric Therapies, 11, pp. 1-17.

14 Colby, K. M. (1973) The Rationale for Computer-Based Treatment of Language Difficulties in Nonspeaking Autistic Children. Journal of Autism and Childhood Schizophrenia, 3 (3), pp. 254 - 260.

15 Cooper, M., Keating, D., Harwin, W. \& Dautenhahn, K (1999) Robots in the Classroom -Tools for Accessible Education. Proc. AAATE Conference 1999, The 5th European Con-ference for the Advancement of Assistive Technology, C. Bühler and H. Knops (Eds.), November, Düsseldorf/Germany, IOS Press, pp. 448-452.

16 Dautenhahn, K. (1997) I could be you - the phenomenological dimension of social under-standing. Cybernetics and Systems Journal, 28(5), 417-453.

17 Dautenhahn, K. (1998) The Art of Designing Socially Intelligent Agents Science, Fiction, and the Human in the Loop. Special Issue "Socially Intelligent Agents", Applied Artificial Intelligence Journal, Vol 12, 7-8, OctoberDecember, pp. 573-617, 1998.

18 Dautenhahn, K. (1999) Robots as Social Actors: AURORA and the Case of Autism. Proc. CT99, The Third International Cognitive Technology Conference, August, San Francisco.

19 Dautenhahn, K. (1999b) Embodiment and Interaction in Socially Intelligent Life-Like Agents. In: C. L. Nehaniv (Ed.): Computation for Metaphors, Analogy and Agent, Springer Lecture Notes in Artificial Intelligence, Volume 1562, Springer, pp. 102-142.

20 Dautenhahn, K. \& Werry, I. (2000). Issues of Robot-Human Interaction Dynamics in the Rehabilitation of Children with Autism. Proc: From Animals To Animats, The Sixth International Conference on the Simulation of Adaptive Behavior (SAB2000), 11 -15 September 2000, Paris, France.

21 Dautenhahn, K. \& Werry, I. (2001) The AURORA Project: Using Mobile Robots in Autism Therapy. Learning Technology online newsletter, publication of IEEE Computer Society Learning Technology Task Force (LTTF), Volume 3 Issue 1, January 2001, ISSN 1438-0625.

22 Druin A. \& Hendler J., Eds, (2000) Robots for Kids: Exploring New Technologies for Learning. Morgan Kaufmann Publishers.

23 Jordan, R. (1999) Autistic Spectrum Disorders - An Introductory

Handbook for Practitioners. David Fulton Publishers, London.

24 Kendon, A. (1980) Features of the Structural Analysis of Human Communicational Behaviour. In: von Raffler-Engel (ed) Aspects of Nonverbal Communication, Swets and Zeitlinger, Lisse, Netherlands, pp. 29-43.

25 Kendon, A. (1990) A Description of Some Human Greetings. In Kendon, Conducting Interaction: Patterns of Behavior in Focused Encounters, Cambridge University Press, Cambridge, UK.

26 Machado, I. \& Paiva, A. (2000) The child behind the character. Proc. Socially Intelligent Agents - The Human in the Loop, AAAI Press, Technical report FS-00-04, pp. 102-106.

27 Magnusson, M.S. (1996) Hidden Real-Time Patterns in Intra- and Inter-Individual Behavior: Description and Detection. European Journal of Psychological Assessment 12(2), pp. 112-123.

28 Marsella, S. C., Johnson, W. L., \& LaBore, C. (2000) Interactive Pedagogical Drama. Proc. of the Fourth International Conference on 
Autonomous Agents, June 3-7, Barcelona, Spain, ACM Press, pp. 301-308.

29 Michaud, F., Clavet, A., Lachiver, G., \& Lucas, M. (2000) Designing toy robots to help autistic children -An open design project for Electrical and Computer Engineering education. Proc. American Society for Engineering Education, June 2000.

30 Moore, D. (1998) Computers and people with autism. Communication, Summer 1998, pp. 20-21.

31 Murray, D. (1997) Autism and information technology: therapy with computers. In: S. Powell and R. Jordan: Autism and Learning: a guide to good practice. London: David Fulton, pp. 100-117.

32 Nadel, J., Guerini, C., Peze, A. \& Rivet, C. (1999) The evolving nature of imitation as a format of communication, In: J. Nadel and G. Butterworth (Eds.) Imitation in Infancy, Cambridge University Press, pp. 209-234.

33 Ogden, B \& Dautenhahn, K. (2000) Robotic Etiquette: Structured Interaction in Humans and Robots. Proc. SIRS2000, Symposium on Intelligent Robotic Systems, Reading, UK, pp 353-361

34 Ogden, B. \& Dautenhahn, K. (2001) Embedding Robotic Agents in the Social Environ-ment. Proc. TIMR 2001, Towards Intelligent Mobile Robots: The 3rd British Conference on Autonomous Mobile Robotics and Autonomous Systems, Manchester, 5th April 2001.

35 Ogden, B. \& Dautenhahn, K. (2001) Interactive Vision from the Top Down: Interactional Structure Applied to the Identification and Interpretation of Visual Interactive Behaviour. To be presented at Gesture Workshop 2001, The 4th International Workshop on Gesture and Sign Language Based

Human-Computer Interaction, 18th-20th April 2001, City University, London, UK.

36 Panyan, M. V. (1984) Computer technology for autistic students. Journal of Autism and Developmental Disorders 14(4): 375-382.

37 Papert, S. (1980). Mindstorms: Children, Computers, and Powerful Ideas. Basic Books, New York.

38 Parsons, S., Beardon, L., Neale, H.R., Reynard, G., Eastgate, R., Wilson, J.R., Cobb, S.V., Benford, S.D., Mitchell, P. \& Hopkins, E. (2000) Development of social skills amongst adults with Asperger's Syndrome using virtual environments: the 'AS Interactive' project. Proc. $3^{\text {rd }}$ Int Conf Disability, Virtual Reality \& Assoc. Tech., Alghero, Italy 2000, pp.163-170

39 Plaisant, C., Druin, A., Lathan, C., Dakhane, K., Edwards, K., Vice, J.M., Montemayor, J. (2000) A Storytelling Robot for Pediatric Rehabilitation. Proc. ASSETS '00, Washington, Nov. 2000, ACM, New York.

40 Powell, S. (1996) The use of computers in teaching people with autism. In: Autism on the Agenda: Papers from a National Autistic Society Conference. London: NAS, 1996.

41 Psathas, G. (1995) Conversation Analysis: the Study of Talk-in-Interaction. Sage Publications

42 Russo, D. C. \& Koegel, R. L. \& Lovaas, O. I. (1978) A Comparison of Human and Auto-mated Instruction of Autistic Children. Journal of Abnormal Child Psychology, June, 6 (2), pp. 189-201.

43 Schank, R.C. \& Abelson, R. (1977) Scripts, Plans, Goals and Understanding. Laurence Erlbaum Associates Inc, Hillsdale, NJ.

44 Schulte, J., Rosenberg, C. \& Thrun, S. (1999) Spontaneous Short-term Interaction with Mobile Robots. Proc. ICRA '99, 1999 IEEE Int. Conference on Robotics and Automation, May 10-15, 1999, Marriott Hotel, Renaissance Center, Detroit, Michigan, USA. 
45 Strickland, D. (1996) A virtual reality application with autistic children, Presence: Teleoperators and Virtual Environments 5(3), pp. 319-329.

46 Weir, S. \& Emanuel, R. (1976) Using Logo to catalyse communication in an autistic child. DAI Research Report No. 15, University of Edinburgh. 47 Werry, I. \& Dautenhahn, K. (1999) Applying robot technology to the rehabilitation of autistic children. In Proc. SIRS99, $7^{\text {th }}$ International Symposium on Intelligent Robotic Systems '99, pp. 265-272.

48 Werry, I., Dautenhahn, K. \& Harwin, W. (2001) Evaluating the response of children with autism to a robot. To appear in Proc. RESNA 2001, Rehabilitation Engineering and Assistive Technology Society of North America, Friday, June 22 - Tuesday, June 26, 2001, Reno, Nevada, USA. 